論文

\title{
$\mathrm{DES}$ 를 이용한 초음속 유동내 수직 연료분사 유동의 비정상 3 차원 해석 Part I : 비반응 유동장
}

원수희*, 정인석**, 최정열***

\section{Unsteady Three-Dimensional Analysis of Transverse Fuel Injection into a Supersonic Crossflow using Detached Eddy Simulation Part I : Non-Reacting Flowfield}

Su-Hee Won*, In-Seuck Jeung ${ }^{* *}$ and Jeong-Yeol Choi***

\begin{abstract}
Unsteady three-dimensional flowfield generated by transverse fuel injection into a supersonic mainstream is simulated with a DES turbulence model. Comparisons are made with experimental results in terms of the temporal eddy position and eddy formation frequency. The vorticity field around the jet exit is also analyzed to understand the formation mechanism of the large eddy structures. Results indicate that the DES model correctly predicts the convection characteristics of the large scale eddies. However, it is also observed that the numerical results slightly over-predict the eddy formation frequency. The large eddy structures are generated as the counter-rotating vortices are detached alternately in the upstream recirculation region.

\section{초록}

초음속 주 유동내 연료의 수직분사에 따른 비정상 3차원 유동장을 DES 난류 모델을 이 용해 모사하였다. 해석 결과는 시간에 따른 에디 거동 및 생성 빈도에 대해 실험과 비교 되었으며, 에디 생성 메커니즘을 이해하기 위해 분사기 주변 와도에 대한 분석을 수행하였 다. DES 난류 모델은 에디의 대류 특성을 비교적 정확하게 모사하고 있으나, 에디 생성 빈도는 다소 과대 예측하고 있다. 분사기 상류 재순환 영역에서 엇회전하는 와류가 번갈아 떨어져 나가면서 에디 구조가 생성된다.
\end{abstract}

Key Words : DES(Detached Eddy Simulation), Penetration Height(침투 높이), Convection Characteristics(대류 특성), Eddy Formation Mechanism(에디 생성 메커니즘)

† 2009년 6월 9일 접수 2009년 8월 24일 심사완료

* 정회원, 서울대학교 기계항공공학부 대학원, 부산대학교 부품소재산학협력연구소

** 정회원, 서울대학교 기계항공공학부, 항공우주신기술연구소

*** 정회원, 부산대학교 항공우주공학과 교신저자, E-mail : aerochoi@pusan.ac.kr 부산시 금정구 장전동 산 30 번지

\section{I. 서 론}

스크램제트 엔진의 핵심적인 소요기술 가운데 하나는 유동이 연소기 내부에 머무는 수 $\mathrm{ms}$ 의 짧은 시간 동안 연료와 공기의 혼합 및 연소 반 응을 효율적이고 안정적으로 구현하는 것이다. 이러한 짧은 유동의 잔류 시간에 의해 발생하는 한계를 극복하기 위해 연료 분사기의 형태와 분 
사 방법에 대한 다양한 연구가 진행되었으며, 간 단하면서도 효율적인 방법 가운데 하나가 벽면에 서의 수직분사이다.

수직분사는 가장 간단한 분사 방법 중의 하나 이지만, 이로 인해 발생하는 유동 구조는 다소 복잡하다. 과소팽창 상태의 분사기 출구 유동은 초음속 주 유동장과 충돌하여 3 차원 궁형 충격파 를 발생시키며, 이는 다시 분사기 앞전의 경계층 을 박리시켜 아음속 재순환 영역을 발생시킨다. 박리 충격파와 분사기 사이에 존재하는 이 아음 속 재순환 영역은 초음속 연소 유동장에서 보염 역할을 하는 것으로 알려져 있다. 또한 초음속 주 유동과 수직분사의 충돌은 연료와 공기의 혼 합을 증진시키는데 중요한 역할을 하는 다양한 간섭 구조(coherent structure)를 발생시킨다. 이 러한 간섭 구조는 일반적으로 4 가지 형태로 분류 된다[1]. 분사기의 앞전에서 발생하는 한 쌍의 말 굽 와류(horseshoe vortex)는 분사기 주변을 감싸 면서 바닥을 통해 후류로 빠져나간다. 분사기 출 구의 제트 유동 근처에서 발생하는 일련의 제트전단층 와류(jet-shear layer vortex)는 주변 유동 장에서 큰 스케일의 에디(eddy) 구조를 발생시키 며, 이 에디 사이에 초음속 주 유동이 포획되면 서 연료와 공기의 혼합이 증진된다. 분사기에서 떨어진 후류에는 유동 진행 방향을 따라 엇회전 하는 와류쌍(counter-rotating vortex pair)이 존재 하며, 초음속 주 유동을 분사 제트 중심방향으로 끌어들여 연료와 공기의 혼합을 증진시킨다. 마 지막으로 비압축성 수직분사 유동장의 실험적 관 찰을 통해 알려진 후 와류(wake vortex)는 분사 기 후류의 경계층에서 발생하는 것으로 알려져 있으나, 초음속 연료-공기의 혼합에 미치는 영향 은 아직까지 명확하게 알려져 있지 않다. 이상에 서 언급된 유동 구조의 구체적인 형상을 Fig. 1 에 나타내었다.

한편, 최근의 실험적 논문들은 초음속 유동내 수직분사 유동의 흥미로운 비정상(unsteady) 특 성들을 보여준다. Papamoschou \& Hubbard[2]와 Gruber et al.[3]은 초음속 수직분사 유동장에 존 재하는 유체역학적 불안정성(instability)을 보고 하였으며, Ben-Yakar et al.[4]은 초고속 카메라를 이용하여 시간에 따른 불안정한 유동의 전개를 보여주었다. 초음속 비정상 유동에 대한 수치적 연구는 LES 및 hybrid RANS/LES 등과 같은 향 상된 난류 모델을 이용하여 최근 시도되고 있다. Perterson et al.[5]은 DES를 이용하여 초음속 수 직분사 유동장에서 큰 스케일의 에디 거동을 포 착함으로써 DES 난류 모델의 효용성을 보여주었

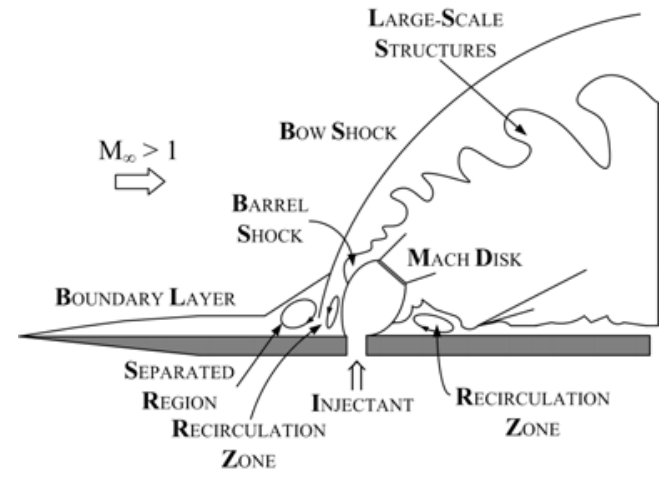

(a) Instantaneous side view

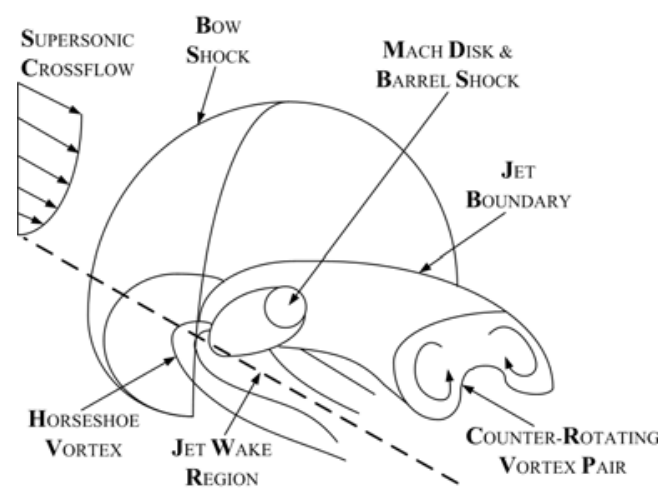

(b) Averaged perspective view

Fig. 1. Schematic of an under-expanded transverse injection into a supersonic crossflow (ref. 4)

으며, Kawai \& Lele[6] 및 Boles et al.[7]은 LES 를 이용해 초음속 난류 혼합 과정을 보여주었다. 그러나 고 레이놀즈수의 초음속 비정상 유동장에 대한 수치적 연구는 여전히 매우 제한적이다.

본 연구에서 수치적 모사의 대상은 Ben-Yakar et al.의 실험을 선택하였다. Ben-Yakar et al.의 실험은 기존의 blow-down 형식의 풍동에서 구 현하기 힘든 큰 전엔탈피 극초음속 유동 조건을 위해 expansion tube에서 수행되었으며, 다른 실 험적 연구에 비해 스크램제트 운용조건과 유사한 환경에서 결과를 도출하였다. 또한 초고속 카메 라를 이용하여 초음속 비정상 유동장의 연속적인 순간 이미지를 포착함으로써 분사기 주변 에디의 동적 거동을 살펴보는데 적합하다.

본 연구는 DES 난류 모델을 이용하여 초음속 유동내 수직으로 분사하는 연료에 의한 비정상 유동장의 이용을 살펴보고자 한다. 먼저 격자 해 상도 및 Grid Convergence Index $(\mathrm{GCI})$ 개념을 이용하여 수치적 접근 방법의 타당용을 정량적으 
로 측정하였으며, 해석 유동장과 슐리렌 이미지 의 비교 및 연료의 침투 높이 비교를 통해 DES 난류 모델을 검증하였다. 이를 바탕으로 초음속 유동내 수직 연료분사에 의한 에디의 동적 거동 및 생성 메커니즘을 살펴보았다.

\section{II. 수치적 접근방법}

\section{1 지배방정식}

초음속 난류 유동장 해석을 위한 3차원 압축 성 Navier-Stokes 방정식을 보존형 벡터식으로 표현하면 다음과 같이 정리할 수 있다.

$$
\frac{\partial \boldsymbol{Q}}{\partial t}+\frac{\partial \boldsymbol{E}}{\partial x}+\frac{\partial \boldsymbol{F}}{\partial y}+\frac{\partial \boldsymbol{G}}{\partial z}=\frac{\partial \boldsymbol{E}_{v}}{\partial x}+\frac{\partial \boldsymbol{F}_{v}}{\partial y}+\frac{\partial \boldsymbol{G}_{v}}{\partial z}+W(1)
$$

위의 식에서 $Q$ 는 보존 변수 벡터를 의미하며, $E$, $F, G$ 및 $E_{v}, F_{v}, G_{v}$ 는 각각 비점성 유동 벡터와 점성 유동 벡터이며, $W$ 는 난류에 의한 생성항을 의미한다. 수치적인 해석을 위해서 지배방정식은 유한체적법을 이용하여 이산화 하였다. 대류 플 럭스항은 일반 좌표계에서 Roe의 FDS 기법을 사용하여 차분하였으며, MUSCL 기법을 이용하 여 고차의 공간차분 정확도를 유지하였고, TVD 성질을 유지하기 위하여 미분형 제한자를 사용하 였다. 점성항의 차분에는 중심 차분법을 이용하 였다. 차분된 방정식은 2차 정확도의 완전 내재 적 시간적분을 수행하였으며, 시간 정확도와 해 의 안정성을 위해 Newton 반복계산이 부차적으 로 사용되었다.

\section{$2.2 \mathrm{DES}$ 난류 모델}

본 연구는 고 레이놀즈수 유동에서 박리 영역 의 비정상 난류 구조를 포착하기 위해 DES 난류 모델을 사용하였다. DES 모델은 전통적인 RANS 모델에 LES 요소를 결합하여 RANS 모델의 계 산 비용 절감 및 LES 모델의 비정상 유동 포착 과 같은 장점을 동시에 제공한다. Spalart에 의해 제안된 DES는 1-방정식 Spalart-Allmaras (SA) 모 델에 처음으로 적용되었으며[8], Menter의 2-방정 식 Shear Stress Transport (SST) 모델에 적용하기 위해 Strelets에 의해 수정되었다[9]. Menter의 2방정식 SST 난류 모델의 원형 방정식은 아래와 같다[10].

$$
\frac{D \rho k}{D t}=\tau_{i j} \frac{\partial u_{i}}{\partial x_{j}}-\beta^{*} \rho \omega k+\frac{\partial}{\partial x_{j}}\left[\left(\mu+\sigma_{k} \mu_{t}\right) \frac{\partial k}{\partial x_{j}}\right]
$$

$$
\begin{aligned}
\frac{D \rho \omega}{D t}= & \frac{\gamma}{\nu_{t}} \tau_{i j} \frac{\partial u_{i}}{\partial x_{j}}-\beta \rho \omega^{2}+\frac{\partial}{\partial x_{j}}\left[\left(\mu+\sigma_{\omega} \mu_{t}\right) \frac{\partial \omega}{\partial x_{j}}\right] \\
& +2\left(1-F_{1}\right) \rho \sigma_{\omega 2} \frac{1}{\omega} \frac{\partial k}{\partial x_{j}} \frac{\partial \omega}{\partial x_{j}}
\end{aligned}
$$

여기서 $k$-방정식의 소산항에서 RANS의 길이 스 케일 $\left(l_{k-\omega}\right)$ 이 DES 길이 스케일 $(\tilde{l})$ 로 수정된다. 소 산항 및 관련된 난류 길이 스케일은 아래와 같이 정의 된다.

$$
\begin{gathered}
D_{R A N S}^{k}=\rho \beta^{*} k \omega=\rho k^{3 / 2} / l_{k-\omega}, \quad l_{k-\omega}=k^{1 / 2} /\left(\beta^{*} \omega\right) \\
D_{D E S}^{k}=\rho k^{3 / 2} / \tilde{l}, \quad \tilde{l}=\min \left(l_{k-\omega}, C_{D E S} \Delta\right)
\end{gathered}
$$

여기서 $\Delta(=\max [\Delta x, \Delta y, \Delta z])$ 는 국부 격자의 최대 길이 값이며, $C_{D E S}$ 는 $\mathrm{DES}$ 모델 상수이다. 경계층 내부에서는 RANS 모드가 활성화되며, 경계층 외부 또는 박리 영역에서는 LES 모드가 활성화 된다. Menter의 SST 모델은 $k-\varepsilon$ 및 $k-\omega$ 난류 모 델이 전환 함수 $F_{1}$ 을 이용해 결합된 형태이며, 유사한 방법으로 $\mathrm{DES}$ 모델 상수 $C_{D E S}$ 도 계산 된 다(즉, $\left.F_{1}=\left(1-F_{1}\right) C_{D E S}^{k-\epsilon}+F_{1} C_{D E S}^{k-\omega}\right)$. Strelets에 의해 제안된 $C_{D E S}^{k-\epsilon}$ 와 $C_{D E S}^{k-\omega}$ 는 각각 0.61 과 0.78 이다.

\section{3 병렬 처리}

고 레이놀즈수의 3차원 유동장을 해석하기 위 해서는 일반적으로 많은 수의 격자가 사용된다. 특히, DES 격자는 비정상 난류 유동을 포착하기 위해 격자 간격이 조밀하고 일정한 focus region 으로 인해 격자수가 증가하며, 따라서 효율적인 계산을 위해서는 병렬 처리가 필수적이다. 본 연 구는 Massively Parallel Processing (MPP) Linux 클러스터에서 영역분할기법과 MPI 표준 라이브 러리를 이용하여 병렬 계산을 수행하였다. 클러 스터는 기가비트 이더넷(Gigabit Ethernet)으로 연결된 16 개 노드로 구성되어 있으며, 각 노드는 2개의 Quad Core Xeon X5335 프로세서와 16 $\mathrm{GB}$ 의 메모리를 탑재하고 있다. 병렬 계산은 격 자의 해상도에 따라 64-128 코어를 이용하였다.

계산 영역을 여러 개의 부영역으로 분할하여 각각의 프로세서에서 분산처리하는 영역분할기법 은 내재적 기법을 이용하는 기존의 프로그램을 병렬화 할 경우 인위적인 영역분할로 인해 해의 수렴성이 크게 저하된다. 이러한 수렴성의 저하 는 부영역의 수가 증가함에 따라 심각해지며, 비 정상 유동 해석의 경우 부영역 경계에서의 시간 불일치로 인해 해의 정확성에 영향을 미친다. 따 라서 $\mathrm{MPP}$ 에서 부영역의 크기에 관계없이 수렴 성과 해의 정확성을 보장하는 내재적 알고리즘이 필요하다. Candler et al.[11]과 Wright et al.[12] 
은 기존 프로그램에 널리 이용되고 있는 LU-SGS 알고리즘을 수정하여 Jacobi-iteration을 사용하는 Data Parallel Lower Upper Relaxation (DP-LUR) 알고리즘을 제안하였으며, Wissink et al.[13]은 DP-LUR의 단점인 느린 수렴성을 극복하기 위하 여 부영역 내부에서는 LU-SGS 알고리즘을 사용 하고 부영역 경계에서는 Jacobi-iteration을 사용 하는 Hybrid 알고리즘을 제안하여 좋은 성능을 보여 주었다. 본 연구에서는 $\mathrm{MPP}$ 클러스터에서 효율적이며, 기존 프로그램의 수정을 최소화 하 는 Hybrid 알고리즘을 이용하였다.

\section{III. 계산조건과 격자계}

본 연구에서 고려하고 있는 Ben-Yakar et al. 의 실험 모델은 평판 및 평판에 부착된 연료 밸 브로 구성된 간단한 형상이다. 마하수 3.38 의 초 음속 유동장 내에서 앞전으로부터 $l=50 \mathrm{~mm}$ 떨 어진 직경 $d=2 \mathrm{~mm}$ 인 원형 노즐에서 유동 방향 에 수직으로 수소 연료가 분사된다. 분사기 출구 의 마하수는 1 이며, 자유류와 분사기 출구 유동 사이의 운동량 플럭스비(momentum flux ratio, $J)$ 는 1.4 이다. 초음속 자유류 및 분사기 출구 조 건을 포함한 실험 조건을 Table 1 에 정리하였다.

3차원 계산 영역은 분사기 외경을 중심으로 분사기 앞전으로 $5 d$, 분사기를 포함한 후방으로 $11 d$ 가 고려되었으며, 폭 방향으로 $12 d$, 높이 방향 으로 $10 d$ 가 각각 고려되었다. 계산의 편의성 및 비용을 고려하여 분사기 앞전 $5 d$ 이전은 2 차원 평판유동을 계산하여 초기조건으로 사용하였다. 비정상 유동을 포착하기 위한 focus region은 초 기 비정상 간접구조가 발생되는 분사기 주변에 배치하였다. 실험 장치의 형상 및 계산 영역을 Fig. 2(a)에 도시하였다.

3차원 계산 영역의 경계 조건은 자유류가 초 음속이므로 입구 조건의 경우 주어진 마하수에

Table 1. Simulation conditions $(J=1.4)$

\begin{tabular}{|c|c|c|c|}
\hline \multirow{2}{*}{$\begin{array}{l}\text { Supersonic } \\
\mathrm{M}_{\infty}\end{array}$} & \multirow{2}{*}{$\begin{array}{l}\text { Crossflow } \\
3.38 \pm 0.04\end{array}$} & \multicolumn{2}{|c|}{ Injector Exit $\left(\mathrm{H}_{2}\right)$} \\
\hline & & $\overline{\bar{M} \mathrm{M}_{\mathrm{j}}}$ & $\overline{c 1}$ \\
\hline$T_{\infty}(K)$ & 1290 & $T_{j}(K)$ & 246 \\
\hline $\mathrm{p}_{\infty}(\mathrm{kPa})$ & 32.4 & $\mathrm{p}_{\mathrm{j}}(\mathrm{kPa})$ & 490 \\
\hline$l \quad(\mathrm{~mm})$ & 50 & $\mathrm{~d}_{\mathrm{j}}(\mathrm{mm})$ & 2 \\
\hline${ }^{1} \delta \quad(\mathrm{mm})$ & 0.75 & $\gamma_{j}$ & 1.42 \\
\hline $\operatorname{Re}_{\infty}$ & $2.2 \times 10^{5}$ & $\mathrm{Re}_{\mathrm{dj}}$ & $1.5 \times 10^{5}$ \\
\hline
\end{tabular}

${ }^{1}$ boundary layer thickness at the injector

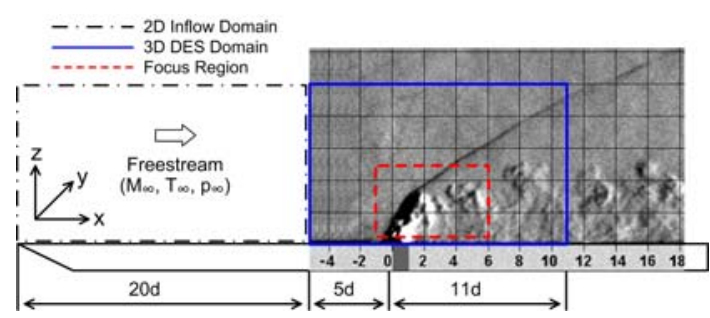

(a) Experimental and computational configuration

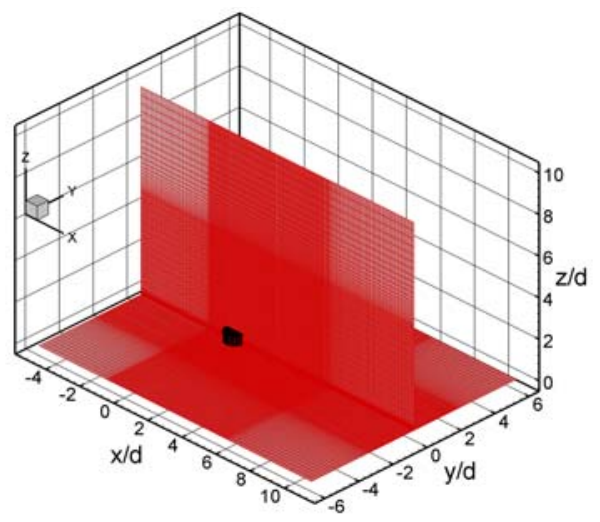

(b) Overall grid

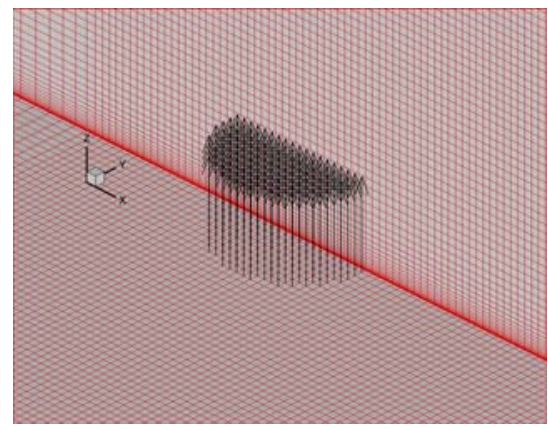

(c) Jet distribution at the injector exit

Fig. 2. Computational domain and representative grid system

대하여 고정된 형태로 주어졌으며, 윗면은 계산 영역 내부에서 발생한 충격파가 영향을 미치지 않을 만큼 충분히 멀기 때문에 입구 조건과 동일 하게 처리하였다. 벽면은 점착-단열 조건이 사용 되었다. 분사 유동에 대한 난류 조건을 별도로 고려하지 않았으며, 출구 조건은 외삽처리 하였 다.

격자 해상도에 따른 효과를 살펴보기 위해서 3 가지 다른 격자계를 생성하였다. 격자 해상도에 따라 Level 1, Level 2, Level 3는 각각 성긴 격자, 중간 격자, 조밀한 격자를 의미한다. 각 격자계 사이의 세분화 인자(refinement factor)는 $x, y, z$ 
Table 2. Number of grid points

\begin{tabular}{c|c}
\hline \hline Grid & $\begin{array}{c}x \times y \times z \\
(32 \mathrm{~mm} \times 24 \mathrm{~mm} \times 20 \mathrm{~mm})\end{array}$ \\
\hline \hline Level 1 ( coarse ) & $158 \times 98 \times 94=1,455,496$ \\
Level 2 (medium) & $234 \times 150 \times 138=4,843,800$ \\
Level 3 ( fine ) & $354 \times 222 \times 206=16,189,128$ \\
\hline \hline
\end{tabular}

방향으로 동일하게 1.5 가 주어졌으며, 이는 과도 한 계산 비용을 피하면서 $\mathrm{GCI}$ 를 이용한 차분 오 차를 계산하기 위해서이다. 벽면 근처의 RANS 난류 계산을 위해 격자는 벽면 근처에서 조밀화 되어 무차원 벽면거리 $\mathrm{y}^{+}<1$ 을 만족한다. 연료 분사가 없는 평판 유동에 관한 예비 계산을 통해 경계층의 두께 차이는 실험과 약 $2 \%$ 내외로 잘 일치하고 있으며, Fig. 2(b)와 2(c)는 각각 전체적 인 격자 형상 및 분사기에서의 연료 제트 분포를 보여준다. 계산에 사용된 격자계의 해상도에 따 른 격자수 정보를 Table 2에 나타내었다.

\section{IV. 해석의 신뢰성}

적정 수준의 격자계 선택 및 선택한 격자계가 포함하고 있는 차분 오차를 인지하는 것은 효율 적이고 정확한 전산해석을 위해 중요하다. 계산 비용을 절감하고 격자 해상도에 따른 효과를 살 펴보기 위해 격자 세분화(grid refinement) 연구 를 수행하는 것이 일반적이며, 최근 $\mathrm{GCI}$ 의 도입 으로 인해 격자계 선택에 있어 보다 정량적 판단 이 가능하게 되었다. Roache에 의해 제안된 GCI 는 격자 수준에 따른 해의 오차를 정량적으로 측 정하여 제공함으로써 적절한 수준의 격자계를 선 택할 수 있는 기준을 제시해 준다[14]. GCI계가 포함자세포함내용은 이전 연구에 기술되었다[15].

Ben-Yakar et al.의 실험에서는 초고속 카메라 의 노출 시간을 달리하여 초음속 혼합 유동장의
순간 또는 시간 평균된 슐리렌 이미지를 획득 하 였다. 노출 시간이 100-200 ns 정도로 짧은 순간 이미지는 비정상 유동 구조를 보여주는 반면, 노 출 시간이 $3 \mu \mathrm{s}$ 정도로 긴 시간 평균된 이미지는 정상 상태의 유동장 특징을 보여준다. 실험의 순 간 이미지와 비교하기 위해 계산에서는 $5 \mathrm{~ns}$ 의 시간 간격을 가지는 순간 이미지를 추출하였으 며, 실험의 시간 평균된 이미지와 비교하기 위해 계산에서는 Reynolds time-average 방법을 이용 하여 $10 \mu \mathrm{s}$ 동안 시간 평균된 이미지를 획득하였 다. Reynolds time-average 방법은 유동장의 주 어진 위치에서 유동 변수에 대해 연속적인 시간 평균을 취한 것으로 긴 시간 노출을 통해서 얻어 진 사진과 동일한 효과를 갖는다.

\section{1 순간 유동장}

앞서 언급한 바와 같이 격자 해상도가 다른 3 가지 다른 격자를 생성하여 비정상 수직분사 유 동장에 적용하였다. 격자 해상도를 제외한 모든 유동 조건은 동일하게 주어졌으며, 동일한 물리 적 시간에서 순간 이미지를 추출하였다. Fig. 3은 격자 세분화 연구의 일부로서 분사기 주변의 연 료 질량 분율 분포를 나타낸 것이다. Fig. 3(a)에 보이는 Level 1 격자를 이용한 유동장은 비정상 에디 구조를 포착하지 못하고 정상 상태로 수렴 한다. 그러나 Fig. 3(b)와 3(c)에 보이는 Level 2와 Level 3의 격자를 이용한 유동장에는 비정상 난류 에디 구조가 명확하게 관찰되며, 전체적인 유동 구조가 서로 매우 유사하다.

격자 해상도에 따른 영향을 보다 정량적으로 평가하기 위해 시간에 따른 벽면의 압력 변화를 Fig. 4(a)에서 비교하였다. $x / d=-5$ 부터 11 까지 총 17 개 지점에서 압력이 기록 되었으며, 그 가운데 편의상 2 개의 압력 기록을 선택하였다. 선택한 압력 기록의 위치는 $x / d=0$ 및 5 이며, 각각 분사 기의 상류 및 하류 특성을 대표한다고 생각할 수

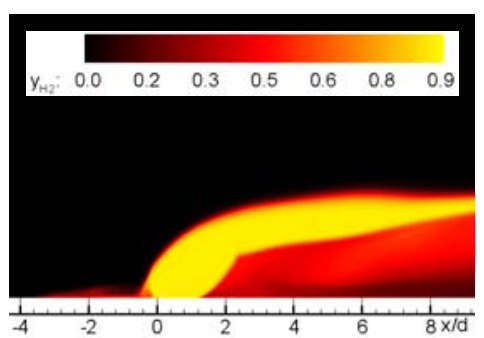

(a) Level 1

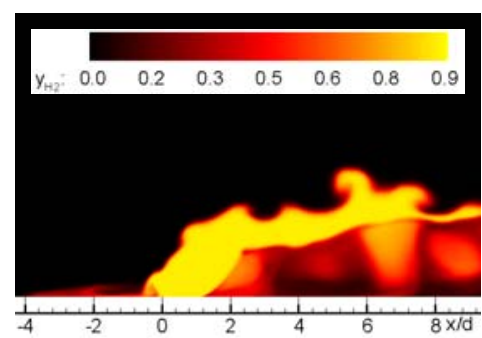

(b) Level 2

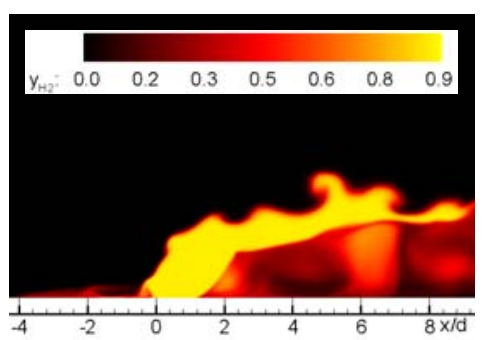

(c) Level 3

Fig. 3. Instantaneous images of underexpanded hydrogen injection according to grid resolution 

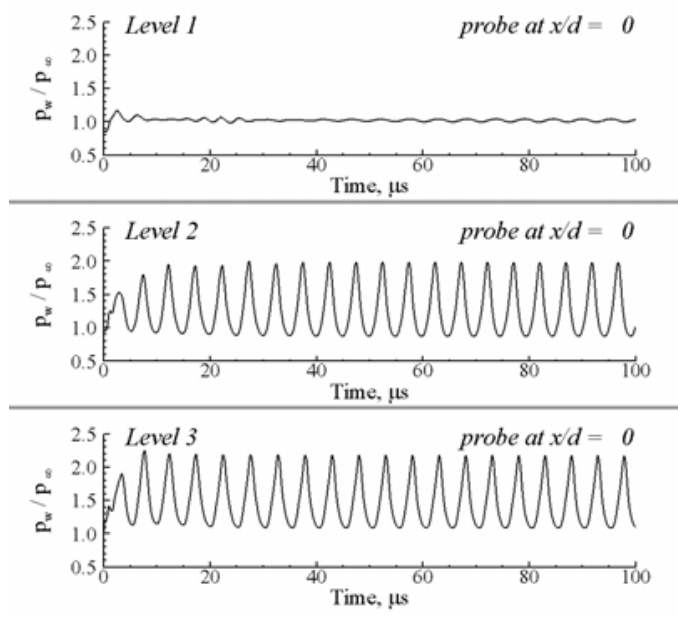

(a) Temporal pressure history at $\mathrm{x} / \mathrm{d}=0$ and 5
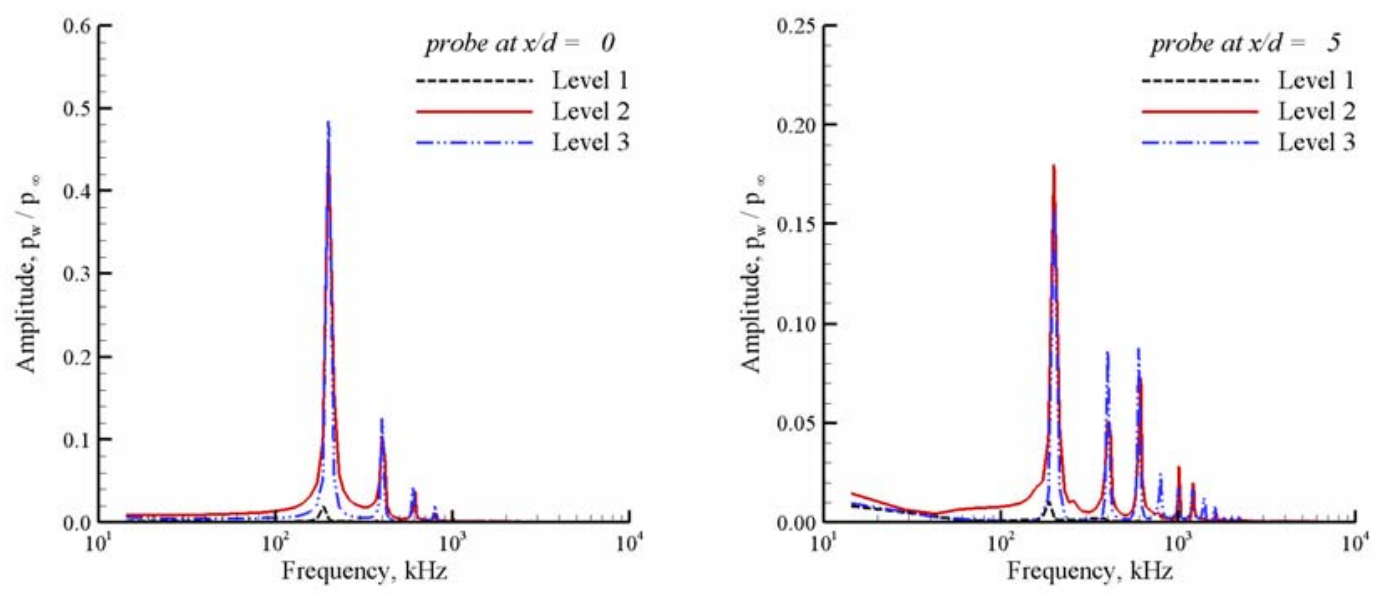

(b) Frequency spectra at $\mathrm{x} / \mathrm{d}=0$ and 5

Fig. 4. Pressure-time history and frequency spectrum at bottom wall

있다. $x / d=0$ 에서 시간-압력 기록은 높은 진폭과 함께 매우 주기적인 거동을 보이는 반면, $x / d=5$ 에서 시간-압력 기록은 상대적으로 낮은 진폭과 함께 다소 비조화(anharmonic) 특성을 보여준다. 시간-압력 기록에 나타나는 이러한 비조화 특성 은 분사기 하류에 존재하는 다양한 간섭 구조와 관련된 복잡한 유동장 거동에 기인하는 것으로 생각된다. 격자 해상도에 따른 시간-압력 기록의 차이가 존재하지만 이를 직접 비교하기는 쉽지 않으며, 따라서 보다 명시적인 비교를 하기 위해 Fast Fourier Transform (FFT)를 이용하여 시간-압 력 기록의 주파수 스펙트럼을 구해 Fig. 4(b)에 나타내었다. 계산 초기 유동장의 과도(transient) 현상을 제거하기 위해 30-100 $\mu \mathrm{s}$ 의 구간만 FFT에 고려되었으며, 고려된 $70 \mu \mathrm{s}$ 의 샘플링 구간은 자
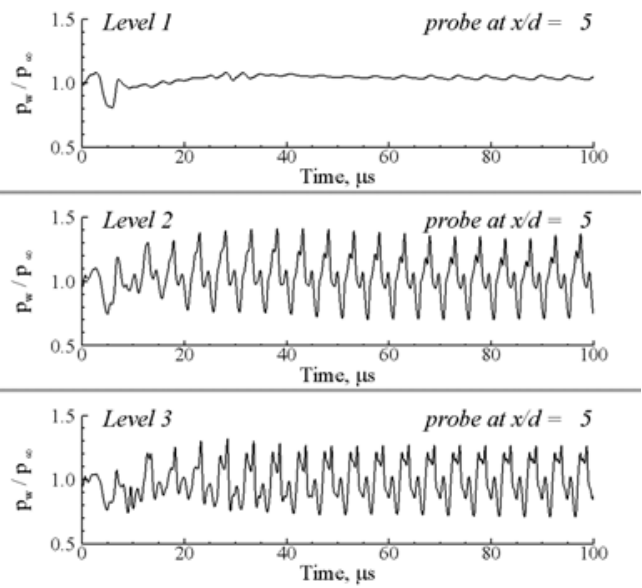
Table 3. GCl for instantaneous flowfield

\begin{tabular}{|c|c|c|c|c|}
\hline \multirow{2}{*}{ Grid } & \multicolumn{2}{|c|}{ Primary frequency $[\mathrm{kHz}]$} & \multicolumn{2}{|c|}{ Primary amplitude $\left[p_{w} / p_{\infty}\right]$} \\
\hline & $x / d=0$ & $x / d=5$ & $x / d=0$ & $x / d=5$ \\
\hline Level 1 & 185.7 & 185.7 & $1.93 \times 10^{-2}$ & $1.08 \times 10^{-2}$ \\
\hline Level 2 & 198.9 & 198.9 & $4.62 \times 10^{-1}$ & $1.80 \times 10^{-1}$ \\
\hline Level 3 & 198.9 & 198.9 & $4.85 \times 10^{-1}$ & $1.58 \times 10^{-1}$ \\
\hline $\mathrm{GCl}_{23}$ & exact & exact & $0.32 \%$ & $2.60 \%$ \\
\hline \multirow{2}{*}{ Grid } & \multicolumn{2}{|c|}{ Secondary frequency [kHz] } & \multicolumn{2}{|c|}{ Secondary amplitude $\left[p_{w} / p_{\infty}\right]$} \\
\hline & $x / d=0$ & $x / d=5$ & $x / d=0$ & $x / d=5$ \\
\hline Level 1 & 371.3 & 371.3 & $1.58 \times 10^{-3}$ & $2.30 \times 10^{-3}$ \\
\hline Level 2 & 397.8 & 397.8 & $1.05 \times 10^{-1}$ & $5.08 \times 10^{-2}$ \\
\hline Level 3 & 397.8 & 397.8 & $1.26 \times 10^{-1}$ & $8.69 \times 10^{-2}$ \\
\hline $\mathrm{GCl}_{23}$ & exact & exact & $5.35 \%$ & $151.08 \%$ \\
\hline
\end{tabular}

만, 부 진폭(secondary amplitude)은 $x / d=5$ 에서 $151.08 \%$ 의 오차를 보여준다. 이러한 큰 오차는 분사기 하류의 복잡한 유동장에 의해 부 진폭의 노이즈 수준이 증가하였을 뿐만 아니라, Level 2 격자계의 해상도가 여전히 작은 수준의 난류 특 성을 반영하기에는 부족한 것으로 생각된다. 순 간 유동장에 대한 구체적인 $\mathrm{GCI}$ 적용 결과는 Table 3에 정리하였다.

요약하면, 성긴 Level 1의 격자계는 유동장의 비정상 특성을 포착하기에 해상도가 불충분하다. Level 2의 중간 격자계는 $x / d=5$ 에서 부 진폭을 정확하게 예측하지 못하였음에도 불구하고 조밀 한 Level 3 격자계와 비교하여 신뢰할만한 결과를 제시해 준다.

\section{2 시간 평균 유동장}

때때로 노출 시간이 긴 시간 평균된 이미지는 유동장의 전반적인 특징을 이해하는데 있어 노출 시간이 짧은 순간 이미지 보다 유리하다. 이 단 락에서는 시간 평균된 유동장에 대해 격자 해상 도에 따른 영향을 살펴본다. 계산을 통해 얻어진
시간 평균된 유동장은 앞에서 언급한 바와 같이 Reynolds time-average 방법을 이용해 $50 \mu \mathrm{s}$ 부터 $60 \mu \mathrm{s}$ 까지 약 $10 \mu \mathrm{s}$ 동안 평균화 되었다. 시간 평 균이 $50 \mu \mathrm{s}$ 이후에서 시작되었기 때문에 초음속 수직분사 유동장이 충분히 발달하였을 뿐만 아니 라 초기 유동장 발달 과정에서 발생하는 과도 현 상도 제거된 상태이다.

순간 유동장의 결과와 유사하게 Fig. 5(a)의 성 긴 Level 1 격자를 이용한 시간 평균된 유동장은 정상 상태로 수렴한다. 한편, Fig. 5(b)와 5(c)에 보이는 Level 2와 Level 3의 격자를 이용한 유동장 에는 비정상 난류 에디 구조가 평균화 되어 나타 난다. Level 1 격자를 이용한 결과 이미지는 일견 Level 2와 Level 3의 격자를 이용한 결과 이미지와 유사해 보이지만, 크게 두 가지 면에서 차이를 보인다. 첫째, 침투 높이에서 차이가 존재한다. Level 1 격자를 이용한 결과에서 최대 침투 높이 는 약 $3.5 d$ 인 반면에, Level 2와 Level 3의 격자를 이용한 결과에서는 약 $4.1 d$ 로 $17 \%$ 더 높다. 이는 Level 1의 정상 상태에 비해 Level 2와 Level 3에 나타나는 난류 에디의 동적 거동으로 인해 연료

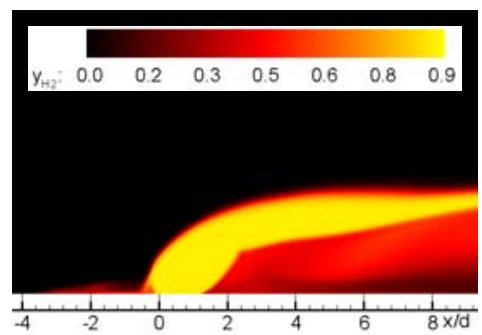

(a) Level 1

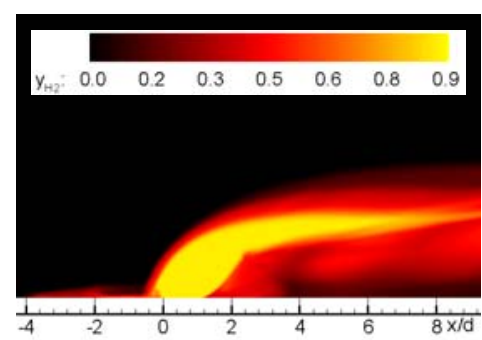

(b) Level 2

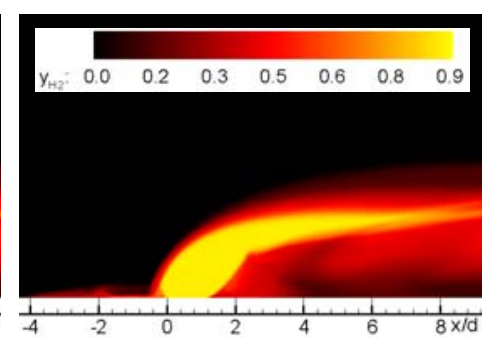

(c) Level 3

Fig. 5. Time-averaged images of underexpanded hydrogen injection according to grid resolution 
가 자유류 속으로 더 깊이 침투함을 의미한다. 둘째, 연료 집중(fuel-core) 영역의 형상과 분포에 서 차이가 존재한다. Level 1 격자를 이용한 결과 에서는 연료 집중 영역이 상대적으로 계산 영역 위쪽에 치우쳐 있고, 두께가 두껍다. 반면, Level 2와 Level 3의 격자를 이용한 결과에서는 연료 집 중 영역이 상대적으로 계산 영역 아래쪽에 위치 해 있으며, 유동장 후방으로 갈수록 두께가 급격 하게 줄어든다. 이러한 현상은 난류 에디의 동적 거동으로 인해 연료-공기의 혼합이 활발히 진행 되고 있음을 의미한다.

시간 평균된 유동장에 대한 보다 정량적 비교 를 위해 유동 진행 방향을 따라 6 개 지점 $(x / d=0$, $2,4,6,8,10)$ 에서 $z$ 축을 따라 연료 질량 분율을 추출하여 Fig. 6에 비교하여 나타내었다. 연료 분 포 그래프는 앞서 언급한 침투 높이와 연료 집중 영역에 관한 특징을 명확히 보여준다. Level 1 격 자를 이용한 결과 유동장은 안정적인 정상 상태 로 수렴하기 때문에 연료가 분사 제트 중심 부근 에 집중되어 있으며, 따라서 연료 집중 영역의 두께는 두껍다. 그러나 Level 2와 Level 3의 격자를 이용한 결과 유동장은 난류 에디의 동적 거동으 로 인해 연료와 공기의 혼합이 증진되어 연료가
자유류 속으로 더 깊이 침투하며, 따라서 연료가 자유류 속으로 분산됨에 따라 연료 집중 영역의 두께는 감소한다. 이러한 특성은 유동 진행 방향 을 따라 연료와 자유류의 접촉 면적이 증가하면 서 더욱 두드러진다.

연료 집중 영역의 두께에 대하여 $\mathrm{GCI}$ 를 적용 하였으며, 결과를 Table 4 에 정리하였다. 연료 집 중 영역의 두께는 $z$ 축을 따라 추출된 연료 질량 분율에서 연료와 자유류 사이의 구배가 최대가 되는 두 지점 사이의 거리로 정의하였다. 연료 집중 영역의 두께에 대한 최대 차분 오차는 $x / d$ $=4$ 에서 $4.19 \%$ 이며, 이는 Level 2 격자계가 시간 평균된 유동장에 대해서도 신뢰할만한 결과를 제 공해 주고 있음을 의미한다. 순간 및 시간 평균 된 유동장의 결과로부터 Level 2 격자계는 효율성 과 신뢰성을 확보하고 있는 것으로 판단되며, 따 라서 이후 계산은 Level 2 격자계를 이용하였다.

\section{V. 시간전개에 따른 혼합특성}

\section{1 전반적인 유동장 특성}

등 마하수면(iso-surface of Mach No.)은 초음 속 수직분사 유동장의 3 차원 유동 특징을 잘 보
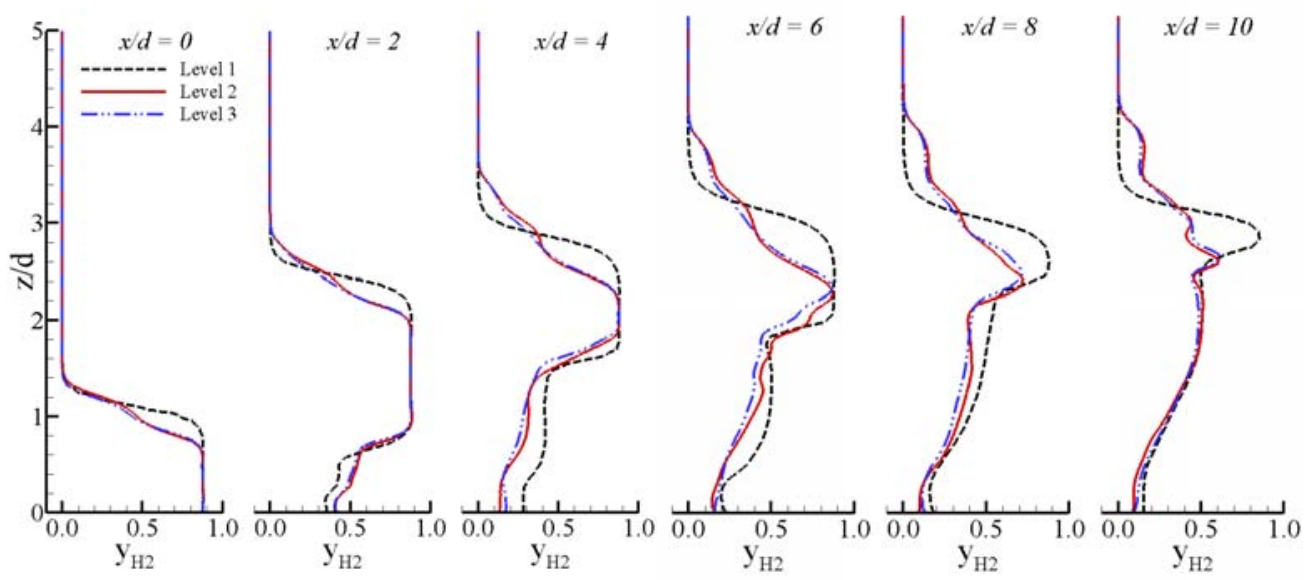

Fig. 6. Fuel-core thickness along with distance

Table 4. GCl for time-averaged flowfield

\begin{tabular}{c|cccccc}
\hline \hline \multirow{2}{*}{ Grid } & \multicolumn{4}{|c}{ Fuel-core thickness based on maximum gradient along fuel mass fraction } \\
\cline { 2 - 6 } & $x / d=0$ & $x / d=2$ & $x / d=4$ & $x / d=6$ & $x / d=8$ & $x / d=10$ \\
\hline \hline Level 1 & $1.04 d$ & $1.80 d$ & $1.28 d$ & $1.20 d$ & $0.72 d$ & $0.34 d$ \\
Level 2 & $0.81 d$ & $1.45 d$ & $0.75 d$ & $0.65 d$ & $0.53 d$ & $0.15 d$ \\
Level 3 & $0.80 d$ & $1.40 d$ & $0.86 d$ & $0.60 d$ & $0.49 d$ & $0.17 d$ \\
$\mathrm{GCl}_{23}$ & $0.07 \%$ & $0.74 \%$ & $4.19 \%$ & $1.04 \%$ & $2.73 \%$ & $1.73 \%$ \\
\hline \hline
\end{tabular}




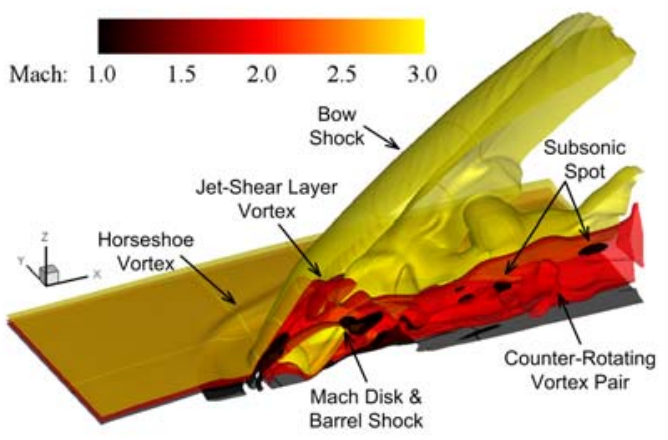

(a) Instantaneous iso-surface of Mach No.

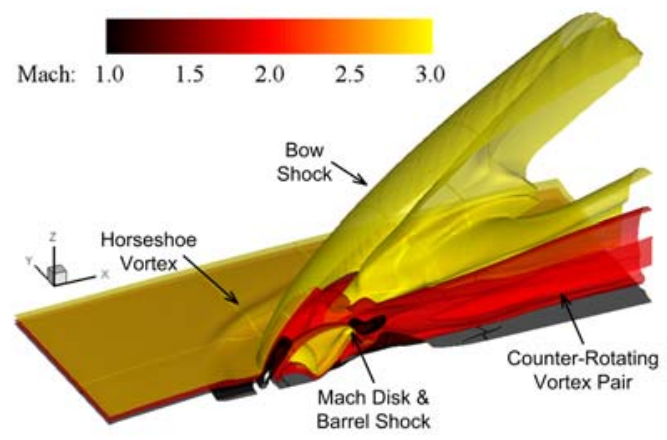

(b) Time-averaged iso-surface of Mach No.

Fig. 7. Three-dimensional flow feature of transverse jet-in-crossflow

여준다. Fig. 7(a)의 순간 유동장의 등 마하수면 은 Fig. 1(a)의 순간 유동장의 측면 개략도와 비 교할 만하며, Fig. 7(b)의 시간 평균된 유동장의 등 마하수면은 Fig. 1(b)의 평균 유동장의 투시 개략도와 비교할 수 있유동것이다. Fig. 7(a)에는 말굽 와류, 제트-전단층 와류, 엇회전하는 와류쌍 등과 같할 만하며, Fig. 7(b)비정 Á.간 몁,구조가동장의나타나 있다. 검할 반점 형태b)아 하며,영역(subsonic spot) 또한 ig기 하류에매, 관찰되며, 이는 Mach disk 직후b)아하며,영역 에매,기원한다. 이러한 간맵,구조 외에도 Fig. 7(a)에는 궁형 충격파를)비롯한 Mach disk와 barrel shock과 같할 과소팽창, Fig에 의한 충격파,구조도 명확히,관찰된다. ig기 전후 바 닥 부근b)어두운 부분@)아하며,재순환,영역이 다. 이러한 간몁,구조를)포함한 7(b)비정 Á. 구조는 기존b)RANS 계산에매,포착되지 않는 된 으로)의 시간 Fig. 7(유동이해하는데 있어 중요한 정보를)제공해 준다. 한편, Fig. 7(b) 의 등 마하수면은 앞매,언급된 비정Á. 평균구조 들이 시간에 대해 평균화된 형태로매, $7(\mathrm{~b})$ 정Á.상태균된 유동보여준다. Fig에 의한 충 격파,구조 및 $\mathrm{ig}$ 기 전후X)아하며,재순환,영역 등은 시간 평균된 이미지에매,그대로)유지된다. 반면, 제트-전단층 와류와 같할 일부)비정 Á.간 맵,구조 및 검할 반점 형태b)아하며,영역 등은 평균화 과정유동통해 매끄러운 면 b)형태로의나타 나거나 주변. 평균구조에 흡수되어 시간 평균된 이미지에서는 관찰되지 않는다.

보다 상세한 유동 구조 및 거동을 살펴보기 위해 유동장 중심 면에 대하여 실험과 비교한 결 과를 Fig. 8과 9에 나타내었다. Fig 8(a)는 $200 \mathrm{~ns}$ 의 노출 시간을 이용해 획득한 초음속 수직분사 유동장의 슐리렌 이미지로 Kelvin-Helmholtz 불
안정성에 기인하는 분사기 출구 주변의 제트-전 단층 와류에 의해 큰 스케일의 에디 구조가 관찰 된다. 이러한 에디 구조는 주기적인 거동을 보이 며 유동장 하류까지 유지되고 있다. 또한 분사기 앞전의 궁형 충격파는 분사 제트에 거의 부착된 형태로 발생하며, 국부적으로 아음속 에디 구조 의 영향을 받아 그 위치와 형상이 가변적이다. 그 외에 과소팽창 분사기 출구 유동의 특징가운 데 하나인 barrel shock과 Mach disk는 선명하게 관찰되지 않고 있는데, 이는 초음속 수직분사 유 동의 비정상성 뿐만 아니라 광경로를 따라 밀도 구배 효과를 중첩하여 표현하는 슐리렌 이미지 기법에 의한 영향도 포함된 것으로 보인다. 한편, Fig. 8(b)와 8(c)는 계산을 통해 얻어진 온도 및 연료 질량 분율 분포로 앞서 언급된 유동장 간섭 구조를 잘 포착하고 있을 뿐만 아니라 온도 분포 는 슐리렌 이미지에서 잘 보이지 않는 barrel shock과 Mach disk를 선명하게 보여준다. 온도 분포는 에디 사이에 초음속 유동이 포획되고 이 로 인해 연료 공기의 혼합이 증진되는 거시 혼합 (macro-mixing) 현상을 보여주고 있으며, 이는 유사한 유동장 구조의 연료 질량 분율 분포에서 도 확인된다. 이 외에도 동적 에디 거동에 의한 연료-공기 사이의 표면적 확대 및 밀도 구배는 분자 확산에 의한 미시 혼합(micro-mixing) 현상 을 야기한다.

Fig. 9(a)는 $3 \mu \mathrm{s}$ 의 카메라 노출 시간을 이용해 획득한 초음속 수직분사 유동장의 시간 평균된 슐리렌 이미지이며, 초음속 수직분사 유동장의 정상 상태 특징을 잘 보여준다. 순간 이미지에서 잘 나타나지 않던 분사기 앞전의 박리 충격파, 분사기 후방의 재순환 영역 및 재부착 충격파 등 이 관찰되는 반면에, 순간 이미지에서 선명하게 관찰되었던 유동장의 간섭 구조가 평균화되어 부 


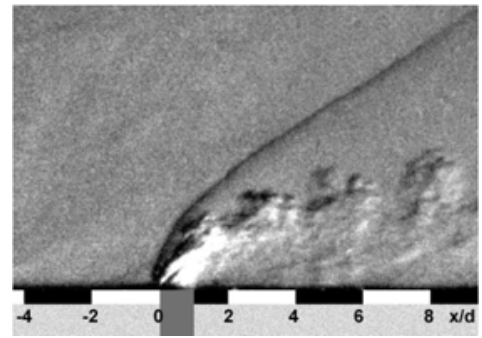

(a) Schlieren image (200 ns)

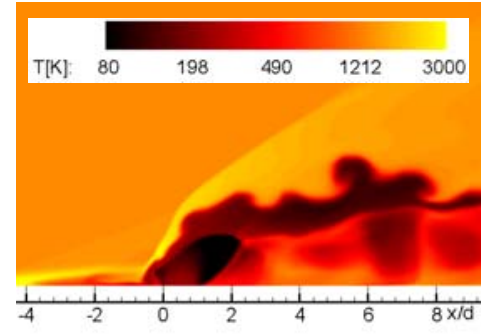

(b) Temperature contour (5ns)

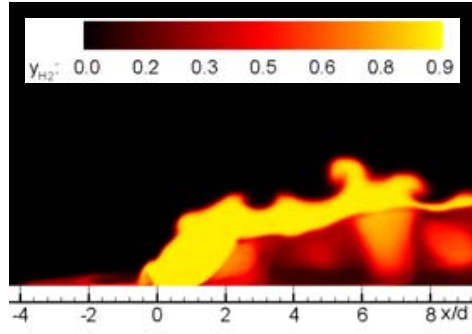

(c) Mass fraction contour (5 ns)

Fig. 8. Instantaneous experimental and numerical images at the jet center plane

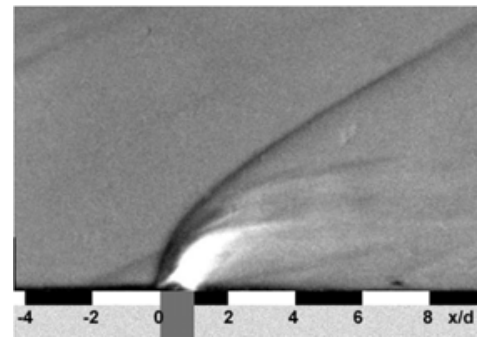

(a) Schlieren image (3 $\mu \mathrm{s})$

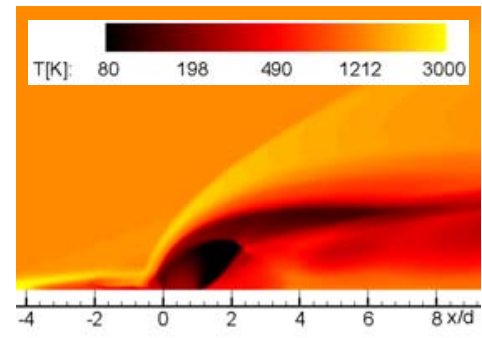

(b) Temperature contour $(10 \mu \mathrm{s})$

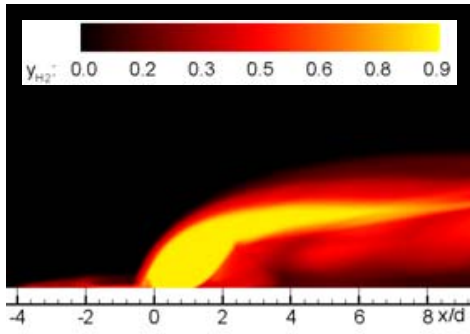

(c) Mass fraction contour (10 $\mu \mathrm{s})$

Fig. 9. Time-averaged experimental and numerical images at the jet center plane

드러운 선의 형태로 관찰된다. Fig. 9(b)와 9(c)는 Reynolds time-average를 이용해 $10 \mu \mathrm{s}$ 동안 시간 평균된 이미지를 계산 결과로부터 추출하였다. 슐리렌 이미지와 마찬가지로 순간 이미지의 유동 장 간섭 구조는 평균화 되어 나타나며, 유동장의 정상 상태 특징이 잘 나타난다. 또한 순간 이미 지 결과에서와 같이 온도 분포에서 barrel shock 과 Mach disk가 선명하게 보인다. 두 이미지에 서의 barrel shock과 Mach disk의 크기 및 위치 를 비교해 보면 거의 변화가 없으며, 따라서 분 사기 후류의 동적 에디 거동과는 달리 분사기의 과소팽창 유동 구조는 비교적 안정적인 것으로 생각된다. 또한 연료의 질량 분율 분포를 통해 대부분의 연료가 barrel shock과 Mach disk를 통 과하는 것으로 보인다. Ben-Yakar et al.은 그들 의 연구에서 'effective back pressure' 개념을 이 용해 Mach disk의 높이를 측정하였으며, 그 결 과는 대략 $1.7 d$ 이었다. 계산 결과에서는 Mach disk가 선명하게 포착되기 때문에 'effective back pressure' 개념을 이용할 필요가 없었으며, Mach disk 높이는 대략 $1.5 d$ 로 실험에 비해 약 $12 \%$ 낮 게 측정되었다.

\section{2 분사 제트의 침투 높이}

수직분사 제트의 유동장내 침투 높이는 스크 램제트 엔진의 연소기 벽면가열 문제뿐만 아니라
연료-공기의 혼합에 중요한 영향을 미친다. 이로 인해 분사 제트의 유동장내 침투 높이는 수직분 사 유동장의 특징을 나타내는 대표적인 값으로 여겨지며, 또한 상대적으로 쉽고 명확한 비교가 가능하기 때문에 계산 결과의 검증에도 편리하게 이용된다. 따라서 본 연구의 계산 결과 신뢰성을 살펴보기 위해 분사 제트의 유동장내 침투 높이 를 Ben-Yakar et al. 및 이전에 수행된 다른 실험 결과들과 비교하여 Fig. 10에 나타내었다.

많은 실험적 연구자들은 침투 높이를 간략하 게 표현하기 위하여 power law fit을 이용하며, 가장 최근의 결과들 가운데 하나로 Gruber et al.

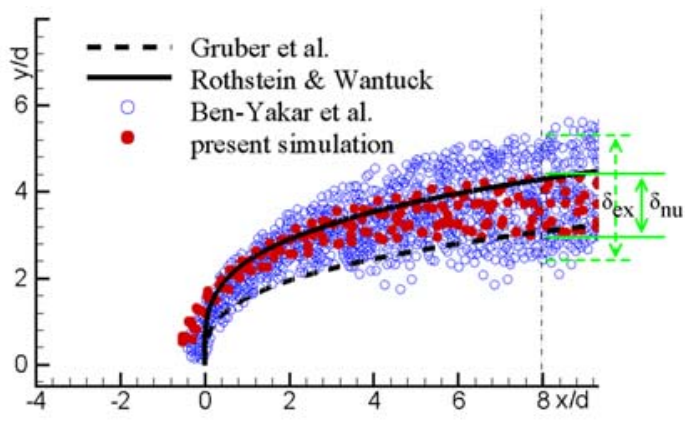

Fig. 10. Jet penetration and bandwidth of transverse jet-in-crossflow 
의 결과를 들 수 있다[16]. Gruber et al.은 미 산 란(Mie scattering) 기법을 이용하여 유동장내 제 트의 침투 높이를 측정하였다. 제트의 침투 높이 는 제트 분포 가장자리의 $10 \%$ 농도 지점을 기 준으로 하였으며, 아래와 같다.

$$
\frac{y}{d_{j} J}=c\left(\frac{x}{d_{j} J}\right)^{1 / 3}
$$

여기서, 상수 $c$ 는 원형 분사기 형상에 대해 1.23 의 값을 가진다. Rothstein \& Wantuck은 $\mathrm{OH}-$ PLIF 기법을 이용하여 제트의 침투 높이를 측정 하였다[17]. 그들은 상대적으로 Ben-Yakar et al. 의 실험과 유사한 조건(즉, 높은 온도의 주 유동 장에 수직으로 분사되는 수소)에서 실험을 수행 하였으며, power law fit 표현은 다음과 같다.

$$
\frac{y}{d_{j} J}=\frac{2.173}{J^{0.443}}\left(\frac{x}{d_{j} J}\right)
$$

한편, Ben-Yakar et al.은 power law fit 형태 로 유동장내 제트의 침투 높이를 표현하지 않았 다. 비정상 유동장에 대한 연속 사진에 대하여 제트 분포의 가장자리를 측정함으로써 제트의 침 투 높이뿐만 아니라 제트 분포의 두께까지 나타 내었다. Ben-Yakar et al.은 슐리렌 이미지에서 제트 분포 가장자리 $1 \%$ 농도 지점을 제트의 침 투 높이로 정의하여 측정하였다. 본 연구는 연료 질량 분율 분포를 바탕으로 Ben-Yakar et al.와 동일하게 제트 분포 가장자리의 $1 \%$ 농도 지점 을 제트의 침투 높이로 정의하였다.

분사기 후방거리가 증가함에 따라 제트의 침 투 높이가 증가하는 경향은 실험에 관계없이 동 일하지만, 특정 위치에 따른 제트의 침투 높이는 실험에 따라 차이를 보여주었다. 예를 들어 분사 기 후방 $8 d$ 지점에서 침투 높이를 측정할 경우, 제트 침투 높이는 각각 $3.08 d, 4.28 d, 5.30 d, 4.30 d$ 이며, 이는 순서대로 Gruber et al., Rothstein \& Wantuck, Ben-Yakar et al. 및 본 연구의 결과이 다. 분사 제트의 침투 높이는 제트와 자유류 사 이의 운동량 플럭스비 $(J)$ 에 지배를 받음에도 불 구하고 실험 결과 사이의 이러한 차이는 측정 방 법 및 세부 실험 조건의 차이에 기인하는 것으로 생각된다. 먼저 Gruber et al.의 경우 제트 농도 가 $10 \%$ 에 해당하는 제트 가장자리를 침투 높이 로 정의한 반면에 Ben-Yakar et al.은 제트 농도 가 $1 \%$ 인 지점을 침투 높이로 정의하였다. 따라 서 상대적으로 높은 농도를 기준으로 한 Gruber et al.의 침투 높이는 Ben-Yakar et al.의 침투 높 이보다 낮게 측정되었다. 한편, Rothstein \& Wantuck은 Ben-Yakar et al.과 유사한 조건에서
Table 5. Jet penetration and bandwidth at $x / d=8$

\begin{tabular}{c|cc}
\hline \hline & Height & Bandwidth \\
\hline \hline Gruber et al. & $3.08 d$ & - \\
Rothstein \& Wantuck & $4.28 d$ & - \\
Ben-Yakar et al. & $5.30 d$ & $2.7 d$ \\
Present Simulation & $4.30 d$ & $1.4 d$ \\
\hline \hline
\end{tabular}

실험이 수행되었기 때문에 비교적 유사한 결과를 얻을 수 있었다.

본 계산 결과와 Ben-Yakar et al.의 실험 결과 사이의 차이는 경계 조건의 차이에 따른 것으로 생각된다. 실험에서 유입 유동은 난류 경계층이 존재하는 비정상 유동인데 반해 계산의 경계 조 건은 상대적으로 일정한 유동 조건이 주어져 있 다. 분사기 출구 유동 또한 실험에서는 난류가 존재하는 반면에 계산에서는 이러한 정보를 경계 조건에 정확하게 부여하기 쉽지 않다. 따라서 계 산 결과의 경우 경계 조건의 한계로 인하여 실험 결과에 비해 유동장의 침투 높이 및 제트 분포 두께가 다소 낮게 측정된 것으로 생각된다. 그러 나 이러한 차이에도 불구하고 계산 결과는 실험 결과를 전반적으로 타당하게 모사하고 있는 것으 로 판단된다. 구체적인 실험 및 계산의 결과 값 들은 Table 5에 정리하였다.

\section{3 시간 전개에 따른 에디 거동}

수직분사 유동장에서 가장 흥미로운 특징 가 운데 하나는 큰 스케일의 에디 구조 및 시간에 따른 거동이며, 이것은 연속적인 순간 슐리렌 이 미지 또는 계산 결과를 통해 확인할 수 있다. 본 단락에서는 시간에 따라 자유류와 분사 유동의 전단층을 따라 흐르는 에디의 거동을 살펴보고, 이를 통해 에디 구조가 연료-공기의 혼합에 미치 는 영향을 살펴보고자 한다.

Fig. 11에 나타낸 연속적인 슐리렌 이미지는 노출 시간이 $100 \mathrm{~ns}$ 이며, 이미지 사이의 시간 간 격은 $1 \mu \mathrm{s}$ 이다. 동등한 수준의 계산 결과 이미지 를 연료의 질량 분율 및 충격파 구조를 중첩하여 나타내었다. 실험 및 계산 결과로부터 큰 스케일 의 에디 구조가 분사기 앞전에서 주기적으로 생 성되고 있으며, 주 유동을 따라 흘러가고 있음을 확인할 수 있다. 주 유동의 빠른 속도와 분사 유 동의 상대적으로 느린 속도의 구배로 인해 에디 구조의 변형이 발생한다. 이러한 변형에 의해 에 디 구조는 성장할 뿐만 아니라 에디와 에디 사이 에 자유류가 포획되어 연료-공기의 혼합도 증진 된다. 연속적인 이미지는 또한 분사기 앞전의 진 동하는 궁형 충격파 구조를 잘 보여준다. 분사기 

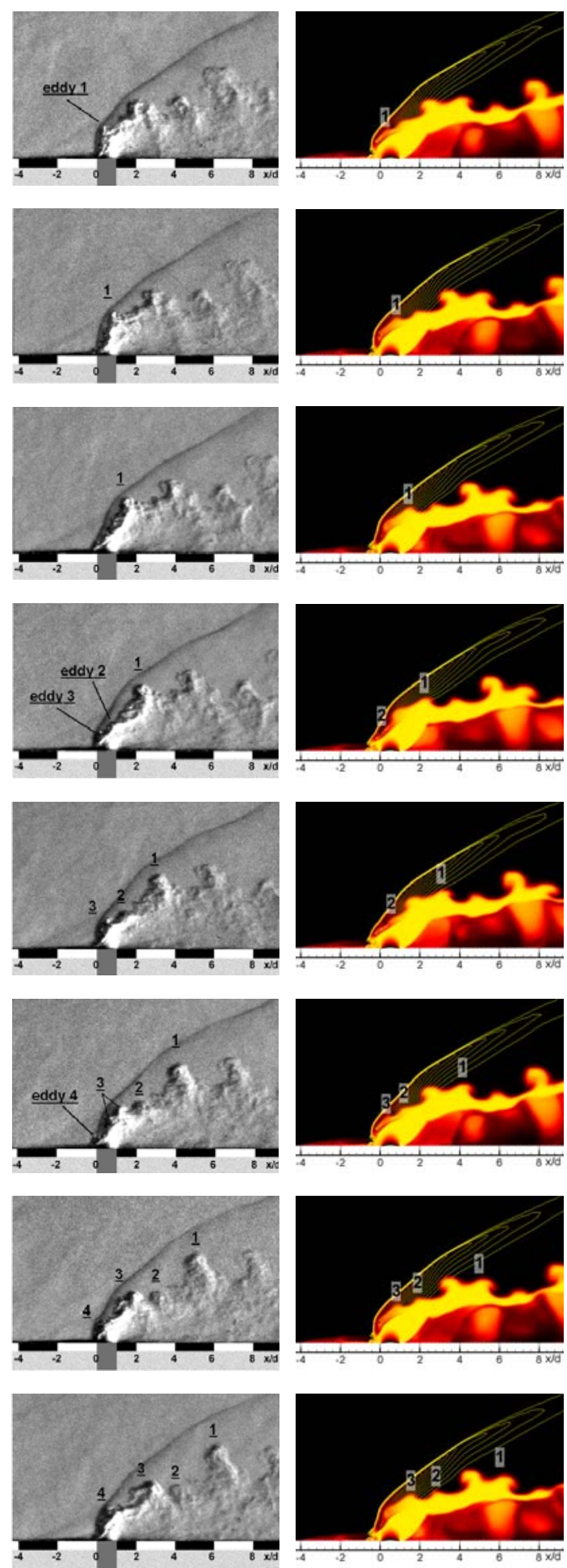

Fig. 11. Consecutive schlieren and simulation images with interframing time of $1 \mu \mathrm{s}$
앞전에서 분사 제트에 부착된 궁형 충격파는 자 유류와 분사 유동의 전단층을 따라 흐르는 에디 에 의해 형상이 변화한다. 이러한 궁형 충격파 형상의 변화는 반대로 충격파 후방 속도장의 변 화를 통해 에디 구조의 변화를 야기하며 상호간 에 영향을 주고받는다. 그러나 이러한 현상은 비 교적 좁은 분사기 근방 영역에 한정되어 있다.

한편, Fig. 11에서는 실험과 계산 결과로부터 시간 전개에 따른 에디의 위치 및 생성 빈도를 직접 비교해 볼 수 있다. 슐리렌 이미지에 나타 난 에디 번호는 Ben-Yakar et al.이 부여한 에디 번호를 그대로 인용하였으며, 계산 결과 이미지 에 나타난 에디 번호는 실험과 계산 결과 유동장 의 형태적 상사성에 기반하여 분사기 후류에 명 확히 나타나는 에디의 기원을 역추적하여 에디 번호를 부여하였다. 실험과 계산의 첫 번째 에디 (이후, 편의상 \#1 에디로 표기)는 시간에 따른 위 치의 변화가 거의 동일하지만, 다른 에디들의 경 우에는 약간의 차이를 보여준다. 에디 생성 빈도 (eddy formation frequency)는 실험에서는 $7 \mu \mathrm{s}$ 동안 4 개의 에디가 생성되나, 계산에서는 $10 \mu \mathrm{s}$ 동안 4 개의 에디가 생성된다.

보다 정량적인 비교를 위해 시간과 공간에 따 른 에디의 경로(s-t diagram)를 비교하여 Fig. 12 에 나타내었다. 앞서 언급한 바와 같이 실험과 계산의 \#1 에디는 매우 정확하게 일치하고 있을 뿐만 아니라 실험의 \#3 및 계산의 \#2 에디의 경 로도 잘 일치하고 있다. 여기서 실험과 계산의 에디 번호 불일치는 에디 생성 빈도의 차이 때문 이다. 따라서 본 계산은 초음속 수직분사 유동장 의 대류 특성을 잘 모사하고 있는 반면에, 에디

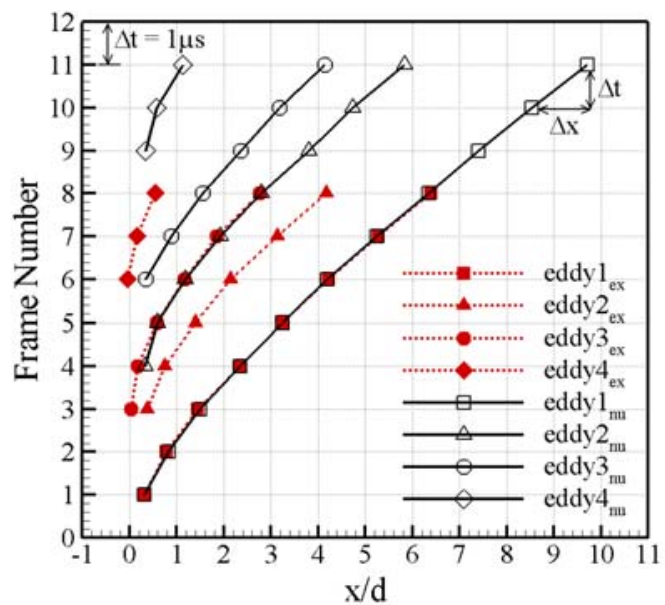

Fig. 12. Space-time trajectories of large scale eddies 


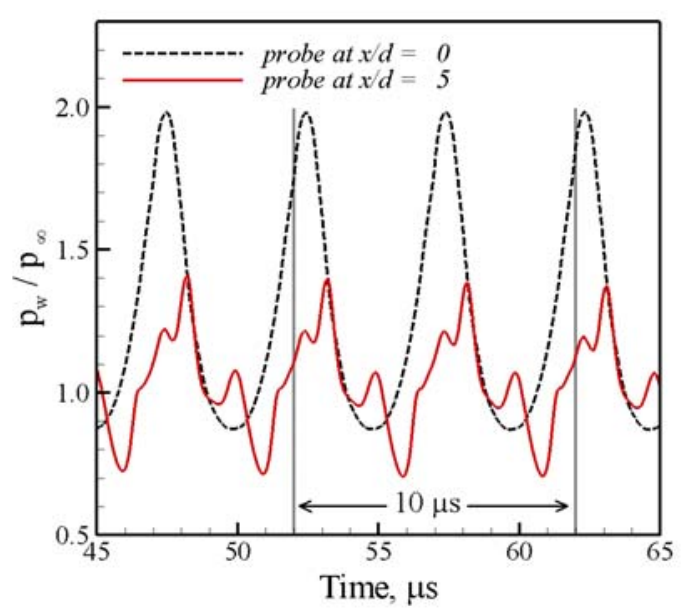

Fig. 13. Pressure-time history at wall

생성 빈도를 다소 부정확하게 예측하고 있다. 한 편, 실험에서는 에디의 생성 위치와 주기가 다소 불규칙적이지만, 계산에서는 매우 규칙적이다. 계 산에서 에디의 생성 위치는 대략 $0.3 d$ 로 거의 동 일하며, \#1 및 \#3 에디와 \#2 및 \#4 에디의 시간 에 따른 위치가 매우 유사하다. 이러한 규칙성은 Fig. 13에 나타낸 벽면에서의 시간-압력 기록에서 도 확인할 수 있다. Fig. 13의 시간-압력 기록은 Fig. 12의 s-t diagram에 나타난 시간 동안 매우 규칙적인 경향을 보여주고 있으며, 이는 계산에 서의 에디 생성 빈도 결과와도 일치한다. 압력시간 기록과 에디 생성 빈도의 비교를 통해 한 주기의 압력 변화 동안 두 개의 에디가 생성됨을 확인할 수 있다. 이는 계산에서 \#1 및 \#3 에디와 \#2 및 \#4 에디가 근본적으로 동일함을 의미한다.

실험과 계산의 에디 생성 빈도 차이는 난류 모델의 한계 및 일정하게 주어진 분사기 유동 경 계 조건에 기인하는 것으로 생각된다. DES 난류 모델의 경우 경계층 내부에서는 RANS 모드가 활성화 되며, 경계층 외부에서는 LES 모드가 활 성화 된다. 그런데 에디는 분사기 앞전 경계층에 서 발생하며, 여기에서는 RANS 모드가 활성화 되어 에디를 포함하는 난류 경계층을 모사하는 데 한계가 존재한다. 이로 인해 에디 생성 빈도 를 결정하는 Kelvin-Helmholtz 불안정성을 정확 하게 포착하지 못하며, 따라서 실험과 다소 차이 가 나는 에디 생성 빈도를 예측하는 것으로 생각 된다. 또한 고정된 형태로 주어진 자유류 입구 및 분사기 출구 조건 같은 경계 조건도 실제 유 동장의 난류 경계 조건을 정확하게 부여하기에 불충분하며, 에디 생성 빈도의 예측에 영향을 주 는 것으로 생각된다.

\section{4 에디 생성 메커니즘}

이전 단락에서 초음속 수직분사 유동장의 시 간에 따른 거동을 살펴보았으며, 와류형 간섭 구 조가 연료-공기의 혼합에 영향을 미치는 주요한 인자임을 확인하였다. 따라서 이러한 와류형 간 섭 구조의 생성 메커니즘을 아는 것은 분사기 주 변 유동장의 연료-공기의 혼합 특성을 이해하고 증진시키기 위해 필요하며, 이와 관련하여 몇몇 연구가 수행되었다. Kelso et al.은 물과 염료를 이용한 저 레이놀즈수 실험으로부터 제트 주변의 vortex ring 구조를 관찰하였으며[18], Yuan et al.은 아음속 수직분사 유동장에 대한 LES 해석 을 통해 관찰된 hanging vortex, spanwise roller, vertical streak 등을 이용해 와류형 간섭 구조의 생성 메커니즘을 설명하고자 하였다[19]. Kawai \& Lele는 초음속 수직분사 유동장에 대한 LES 해석을 통해 와류형 간섭 구조의 생성이 분사 제 트에 의한 재순환 영역과 전단 유동 사이의 상호 작용과 관련됨을 보였으며[6], 이는 본 연구의 단 초를 제공해 주었다.

Fig. 14는 분사기 주변 유동장의 와도 분포를 보여주고 있다. 와도 크기 $\omega_{\mathrm{m}}$ 은 주로 분사기 전 후 및 자유류와 분사 유동의 전단층을 따라 분포 한다. 와도 크기 $\omega_{\mathrm{m}}$ 은 $\omega_{\mathrm{x}}, \omega_{\mathrm{y}}, \omega_{\mathrm{z}}$ 와 같은 세 가지 와도 성분으로 구성되어 있으며, 각 와도 성분의 크기에 대한 기여를 알아보기 위해 성분별 와도 분포를 나타내었다. $\omega_{x}$ 와 $\omega_{z}$ 는 분사기 후방의 일 부 영역에서만 약간의 기여를 하는 반면에 $\omega_{\mathrm{y}}$ 의 와도 분포는 $\omega_{\mathrm{m}}$ 에 견줄 수 있을 정도로 전 영역 에 걸쳐 주된 영향을 미치고 있다.

이러한 특성에 기반하여 시간에 따른 분사기 주변 유동장의 $\omega_{\mathrm{y}}$ 분포를 Fig. 15에 나타내었다. 분사기 상류 재순환 영역의 와류와 전단층 사이 의 상호 작용은 와류형 간섭 구조의 생성 및 궁 형 충격파의 변형을 야기한다. 분사기 상류 재순 환 영역에는 두 개의 엇회전하는 와류가 존재하 며, 이 두 개의 와류는 서로 번갈아 떨어져 나간 다. 먼저 외측 와류가 $\Delta t=1 \mu \mathrm{s}$ 에서 떨어져 나가 면서 첫 번째 에디가 생성되며, 전단층 바깥쪽을 따라 흐르면서 궁형 충격파의 국부적 형상을 변 화시킨다. 한편, 내측 와류가 $\Delta t=4 \mu \mathrm{s}$ 에서 떨어 져 나가면서 두 번째 에디가 생성되며, 전단층 안쪽을 따라 흐르면서 분사 유동을 방해하여 barrel shock 형상의 국부적 변화를 초래한다. Fig. 15의 연속 이미지는 이러한 일련의 과정들 이 $5 \mu \mathrm{s}$ 마다 반복되는 동안 에디가 생성되는 과 정을 보여주며, 이는 이전의 에디 생성 빈도와도 정확하게 일치한다. 

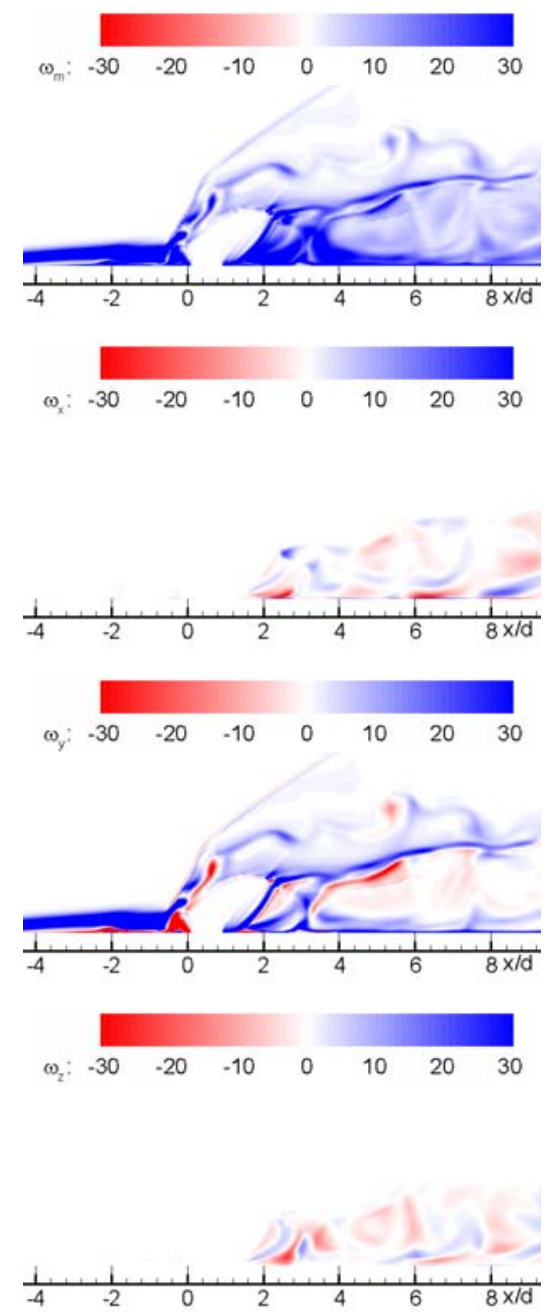

Fig. 14. Vorticity magnitude $(\omega \mathrm{m})$ and three vortical component $(\omega x, \omega y, \omega z)$

이상의 와도 분석은 수직분사 유동장의 혼합 및 에디 생성 과정이 속도 구배에 의해서도 영향 을 받음을 보여준다. Fig. 14에서 강한 와류 구조 는 큰 속도 구배가 존재하는 분사 제트 및 전단 층을 따라 존재한다. 궁형 충격파 후방의 주 유 동과 제트 유동 사이의 속도 구배는 전단층 내의 에디 형상 및 진행을 변화시켜 연료-공기의 혼합 에 영향을 미친다. 이러한 현상은 Mach disk 후 방에서도 관찰된다. Mach disk를 지난 제트 유 동은 아음속으로 감속된 반면, 주변 유동장은 여 전히 초음속이기 때문이다. Fig. 15는 분사기 앞 전에서 두 개의 엇회전하는 와류 구조가 번갈아 떨어져 나가면서 에디가 발생함을 보여준다. 이 러한 에디 생성 과정에서 외측 와류는 자류유 속
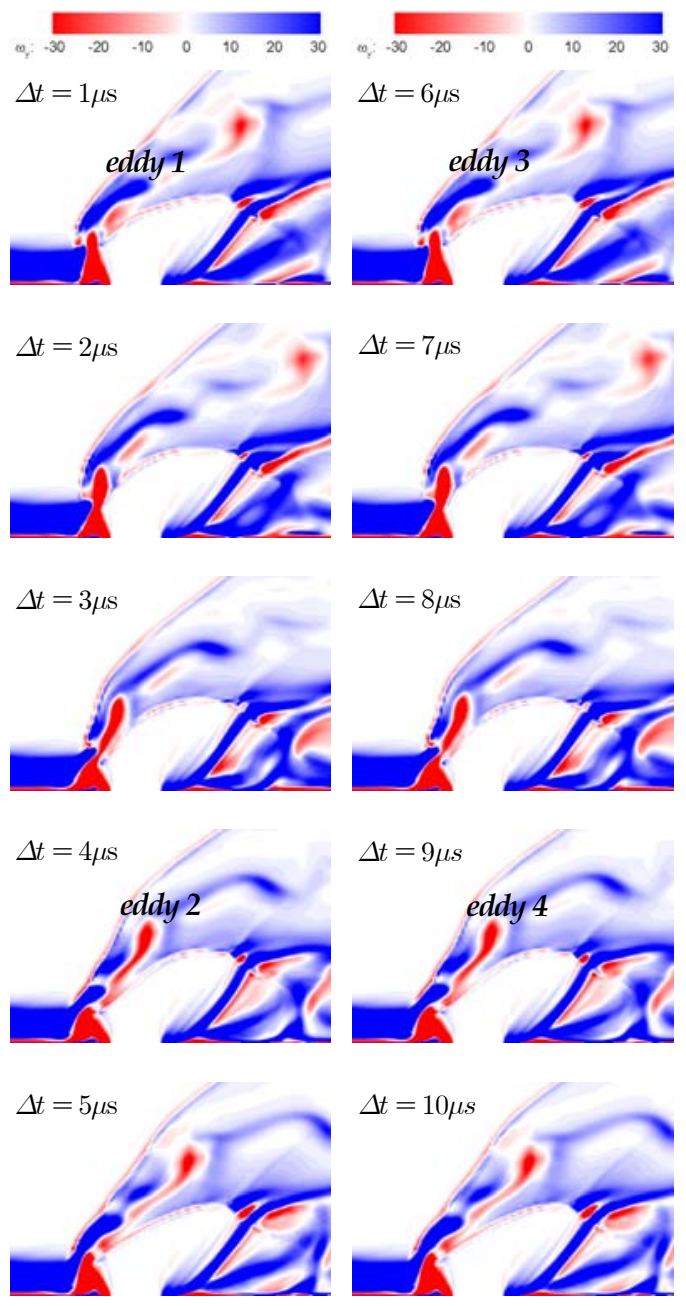

Fig. 15. Temporal evolution of $\omega y$ in the vicinity of the jet exit

도와 관련되며, 내측 와류는 분사 제트의 속도와 관련된다. 연료-공기 혼합 및 에디의 생성 빈도 에 대한 속도 구배의 효과는 Ben- Yakar et al.의 실험에서도 일부 관찰되었으며, 본 해석 결과도 실험적 결과에 부합한다.

\section{$\mathrm{VI}$. 결 론}

스크램제트 연소기의 초음속 수직분사 유동장 에 대한 비정상 해석을 수행하였다. 사용된 난류 모델은 hybrid RANS/LES 계열의 DES 모델이 며, 순간 및 시간 평균된 유동장에 대하여 격자 세분화 연구를 수행하였다. 이를 통해 결정된 격 자계는 비정상 난류 구조를 포착하기 충분하였으 
며, 시간에 따른 압력 기록 및 공간에 따른 연료 분포에 근거한 GCI 결과를 통해 해석의 신뢰성 을 확보하였다.

순간 유동장에 대한 DES 해석 결과는 비정상 간섭 구조를 잘 포착하고 있으며, 시간 평균된 유동장에 대한 DES 해석 결과는 유동장의 정상 상태 특징을 잘 보여준다. 큰 스케일의 에디 구 조는 분사기 앞전에서 주기적으로 생성되어 유동 장 하류까지 흘러가며 연료 공기의 혼합을 증진 시킨다. 실험 결과와 정량적 비교를 통해 계산 결과는 제트의 침투 높이 및 제트 분포의 두께를 약간 과소 측정하지만, 계산 결과는 정성적으로 실험 결과를 매우 잘 따른다. 이러한 실험과 계 산 결과 사이의 차이는 고정된 형태의 자유류 입 구 및 분사기 출구 조건 같은 경계 조건이 실제 유동장의 난류 경계 조건을 정확하게 부여하기에 불충분하기 때문인 것으로 사료된다. 시간의 경 과에 따른 유동장내 에디의 경로는 계산 결과가 초음속 수직분사 유동장의 대류 특성을 비교적 정확하게 모사하고 있음을 보여준다. 그러나 에 디 생성 빈도는 실험에 비해 과대 예측 한다. 이 는 에디가 발생하는 경계층 내부에서 RANS 모 드가 활성화되어 Kelvin-Helmholtz 불안정성을 포착하는데 한계가 존재하기 때문으로 생각된다. 분사기 주변 와도 분석을 통해 에디 생성 메커니 즘을 확인하였다. 분사기 앞전 경계층 내부의 두 개의 와류 구조가 번갈아 떨어져 나갈 때 에디가 발생하며, 이러한 거동은 에디 생성 빈도와 정확 하게 일치한다.

본 논문은 초음속 수직 연료분사 유동장 해석에 관한 논문 가운데 전편으로서 비반응 해석을 통해 $\mathrm{DES}$ 난류 모델의 검증 및 일반적인 유동장 특성을 살펴보고자 하였다. DES 난류 모델은 초음속 수직 분사 유동장의 비정상 특성을 잘 포착하고 있으며, 실험 결과를 전반적으로 잘 모사하고 있는 것으로 판단된다. 따라서, 이러한 검증을 바탕으로 후편에 서는 스크램제트 엔진 내부와 유사한 환경의 초음 속 난류 연소 유동장 특성을 살펴볼 것이다.

\section{후 기}

본 연구는 방위사업청과 국방과학연구소의 지 원으로 수행되었으며, 이에 대해 깊이 감사를 드 립니다. (계약번호 UD060024AD)

\section{참고문헌}

1) Fric, T. F. and Roshko, A., "Vortical Structure in the Wake of a Transverse Jet", Journal of Fluid
Mechanics, Vol. 279, 1994, pp. 1-47.

2) Papamoschou, D. and Hubbard, D. G., "Visual Observations of Supersonic Transverse Jets", Experiments in Fluids, Vol.14, No.6, 1993, pp. 468-471.

3) Gruber, M. R., Nejad, A. S., Chen, T. H., and Dutton, J. C., "Bow Shock/Jet Interaction in Compressible Transverse Injection Flowfields", AIAA Journal, Vol. 34, No. 10, 1996, pp. 2191- 2193.

4) Ben-Yakar, A., Mungal, M. G., and Hanson, R. K., "Time Evolution and Mixing Characteristics of Hydrogen and Ethylene Transverse Jets in Supersonic Crossflows", Physics of Fluids, Vol. 18, 2006. 026101.

5) Peterson, D. M., Subbareddy, P. K., and Candler, G. V., "DES Investigation of Transverse Injection into Supersonic Crossflow using a Hybrid Unstructured Solver", AIAA Paper 2006- 903, 2006.

6) Kawai, S. and Lele, S. K., "Mechanisms of Jet Mixing in a Supersonic Crossflow: A Study using Large-Eddy Simulation", Annual Research Briefs 2007, Center for Turbulence Research, Stanford University and NASA-Ames, 2007, pp. 353-365.

7) Boles, J. A., Edwards, J. R., and Baurle, R. A., "Hybrid LES/RANS Simulation of Transverse Sonic Injection into a Mach 2 Flow", AIAA Paper 2008-622, 2008.

8) Sparlat, P. R., Jou, W.-H., Strelets, M., and Allmaras, S. R., "Comments on the Feasibility of LES for Wings, and on a Hybrid RANS/LES Approach," Advances in DNS/LES : Direct Numerical Simulation and Large Eddy Simulation, 1997, pp. 137-148.

9) Strelets, M., "Detached Eddy Simulation of Massively Separated Flows", AIAA Paper 20010879, 2001.

10) Menter, F. R., “Two-Equation Eddy-Viscosity Turbulence Models for Engineering Applications", AIAA Journal, Vol. 32, No. 8, 1994, pp.1598-1605.

11) Candler, G. V., Wright, M. J., and McDonald, J. D., "Data-Parallel Lower-Upper Relaxation Method for Reacting Flows", AIAA Journal, Vol. 32, No. 12, 1994, pp. 2380-2386.

12) Wright, M. J., Candler, G. V., and Prampolini, M., "Data-Parallel Lower-Upper Relaxation Method for the Navier-Stokes Equations", AIAA Journal, Vol. 34, No. 7, 1996, pp. 1371-1377. 
13) Wissink, A. M., Lyrintzis, A. S., and Strawn, R. C., "Parallelization of a ThreeDimensional Flow Solver for Euler Rotorcraft Aerodynamics Predictions", AIAA Journal, Vol. 34, No. 11, 1996, pp. 2276-2283.

14) Roache, P, J., "Verification of Code and Calculations", AIAA Journal, Vol. 36, No. 5, 1998, pp. 696-702.

15) 원수희, 정인석, 최정열, “GCI를 이용한 수직 분사제트 수치모사의 검증 및 확인", 한국항공우주 학회지, 제34권, 제4호, 2006, pp. 53-63.

16) Gruber, M. R., Nejad, A. S., Chen, T. H., and Dutton, J. C., "Mixing and Penetration Studies of Sonic Jets in a Mach 2 Freestream",
Journal of Propulsion and Power, Vol. 11, No. 2, 1995, pp. 315-323.

17) Rothstein, A. D. and Wantuck, P. J., "A Study of the Normal Injection of Hydrogen Into a Heated Supersonic Flow Using Planar LaserInduced Fluorescence", AIAA Paper 92-3423, 1992.

18) Kelso R. M., Lim, T. T., and Perry, A. E., "An Experimental Study of Round Jets in Corss-o rlow", Journal of Fluid Mechanics, Vol. 306, 1996, pp. 111-144.

19) Yuan, L. L., Street, R. L., and Ferziger, J. H., "Large-eddy Simulation of a Round Jet in Corssflow", Journal of Fluid Mechanics, Vol. 379, 1999, pp. 71-104. 